\title{
Epigenetic upregulation of TET2 is an independent poor prognostic factor for intrahepatic cholangiocarcinoma
}

\author{
Hironori Yamashita ${ }^{1,2,3,4} \cdot$ Aikaterini Tourna $^{3} \cdot$ Masayuki Akita $^{4} \cdot$ Tomoo $_{\text {Itoh }}$ $\cdot$ Shilpa Chokshi $^{3} \cdot$ Tetsuo Ajiki $^{4}$. \\ Takumi Fukumoto ${ }^{4}$ Neil A. Youngson ${ }^{3,6,7} \cdot$ Yoh Zen $^{1,2}$ (i)
}

Received: 19 October 2021 / Revised: 19 November 2021 / Accepted: 5 December 2021 / Published online: 14 December 2021

(c) The Author(s) 2021

\begin{abstract}
Mutations in $I D H 1 / 2$ and the epigenetic silencing of TET2 occur in leukaemia or glioma in a mutually exclusive manner. Although intrahepatic cholangiocarcinoma (iCCA) may harbour $I D H 1 / 2$ mutations, the contribution of TET2 to carcinogenesis remains unknown. In the present study, the expression and promoter methylation of TET2 were investigated in iCCA. The expression of TET 2 was assessed in 52 cases of iCCA (small-duct type, $n=33$; large-duct type, $n=19$ ) by quantitative PCR, immunohistochemistry (IHC) and a sequencing-based methylation assay, and its relationships with clinicopathological features and alterations in cancer-related genes (e.g., KRAS and IDHI) were investigated. In contrast to non-neoplastic bile ducts, which were negative for TET2 on IHC, 42 cases (81\%) of iCCA showed the nuclear overexpression of TET2. Based on IHC scores (area $\times$ intensity), these cases were classified as TET2-high $(n=25)$ and TET2-low $(n=27)$. The histological type, tumour size, lymph node metastasis and frequency of mutations in cancer-related genes did not significantly differ between the two groups. Overall and recurrence-free survival were significantly worse in patients with TET2-high iCCA than in those with TET2-low iCCA. A multivariate analysis identified the high expression of TET2 as an independent prognostic factor $(\mathrm{HR}=2.94 ; p=0.007)$. The degree of methylation at two promoter $\mathrm{CpG}$ sites was significantly less in TET2-high iCCA than in TET2-low iCCA or non-cancer tissue. In conclusion, in contrast to other IDH-related neoplasms, TET2 overexpression is common in iCCA of both subtypes, and its high expression, potentially induced by promoter hypomethylation, is an independent poor prognostic factor.
\end{abstract}

Keywords Cholangiocarcinoma $\cdot$ TET2 $\cdot$ IDH1 $\cdot$ Methylation $\cdot$ Promoter

Hironori Yamashita and Aikaterini Tourna shared first authorship.

Neil A. Youngson and Yoh Zen shared senior authorship.

Neil A. Youngson

n.youngson@ researchinliver.org.uk

Yoh Zen

yoh.1.zen@kcl.ac.uk

Hironori Yamashita

hironori729@gmail.com

Aikaterini Tourna

k.tourna@ researchinliver.org.uk

Masayuki Akita

bokuakkey70033@gmail.com

Tomoo Itoh

tomitoh@med.kobe-u.ac.jp

Shilpa Chokshi

s.chokshi@ researchinliver.org.uk

Tetsuo Ajiki

ajiki@med.kobe-u.ac.jp
Takumi Fukumoto

fukumoto@med.kobe-u.ac.jp

1 Institute of Liver Studies, King's College Hospital, London, UK

2 King's College London, London, UK

3 Institute of Hepatology, Foundation for Liver Research, London, UK

4 Department of Hepato-Biliary-Pancreatic Surgery, Kobe University Graduate School of Medicine, Kobe, Japan

5 Department of Diagnostic Pathology, Kobe University Graduate School of Medicine, Kobe, Japan

6 Faculty of Life Sciences and Medicine, King's College London, London, UK

7 School of Medical Sciences, UNSW Sydney, Sydney, Australia 


\section{Abbreviations}

5hmC 5-Hydroxymethylcytosine

5mC 5-Methylcytosine

$\mathrm{CpG}$ Cytosine guanine dinucleotide

iCCA Intrahepatic cholangiocarcinoma

IHC Immunohistochemistry

FFPE Formalin-fixed paraffin-embedded

WHO World Health Organization

\section{Introduction}

The findings of recent pathological studies, including ours, suggested a dichotomous classification scheme for intrahepatic cholangiocarcinoma (iCCA) with distinct clinicopathological features $[1,8,13]$. Small-duct iCCA histologically characterised by cancer cells arranged in an anastomosing tubular architecture is associated with a history of chronic liver disease $(\sim 50 \%)$, a mass-forming appearance on imaging modalities $(\sim 90 \%)$ and a favourable prognosis (5-year overall survival rate, $\sim 60 \%$ ) [1, 2]. In contrast, large-duct iCCA consisting of duct-forming adenocarcinomas with highly fibrotic stroma shows periductal infiltration, frequent lymph node metastasis and a poor prognosis (5-year overall survival rate, $20 \%$ ) $[1,2]$. This separation scheme has been endorsed by the World Health Organization (WHO) classification of tumours published in 2019 [19].

The two iCCA types have several distinct patterns of genetic abnormalities $[1,8,13]$. Unique molecular events in small-duct iCCA include mutations in $I D H 1, I D H 2$ and $B A P 1$ and the fusion or translocation of FGFR2, while molecular abnormalities in large-duct iCCA are shared with those in extrahepatic cholangiocarcinoma with commonly observed mutations in KRAS and SMAD4 [1, 8, 13]. We previously detected the amplification of MDM2 in $15 \%$ of large-duct iCCA and perihilar cholangiocarcinoma, but not in small-duct iCCA [9]. However, these unique molecular alterations, which drive tumourigenesis, may be present in up to $50 \%$ of iCCA, suggesting that epigenetic alterations are also involved in carcinogenesis. Frequent genetic alterations in epigenetic regulators (e.g., IDH1, IDH2 and ARIDIA) in iCCA also support the importance of DNA methylation changes in the development and progression of iCCA [21].

Tet methylcytosine mioxygenase 2 (TET2) is an $\alpha$-ketoglutarate-dependent enzyme that catalyses the conversion of 5-methylcytosine (5mC) to 5-hydroxymethylcytosine $(5 \mathrm{hmC})$, thereby regulating gene expression and promoting DNA demethylation [25]. Similar to $I D H 1 / 2$ mutations, mutations in and the promoter hypermethylation of TET2 have been confirmed in leukaemias, myelodysplastic syndrome, myeloproliferative neoplasms and low-grade diffuse gliomas $[4,6,10]$. These alterations in IDHI/2 and TET2 are associated with epigenetic defects and a hypermethylation signature [6]. Previous studies reported that an $I D H 1 / 2$ mutation was associated with a better prognosis in patients with glioma, acute myeloid leukaemia or iCCA [16, 20, 23, 27, 28].

Therefore, the present study investigated the expression of TET2 and methylation of the TET2 promoter in iCCA, with the aim of clarifying the clinicopathological significance of molecular alterations in TET2 in iCCA.

\section{Materials and methods}

\section{Case selection}

The present study was approved by the Ethics Committees at our institutes. Fifty-two consecutive patients with iCCA who underwent surgical resection at Kobe University Hospital between 2000 and 2016 were identified in the pathology archives. None had received neoadjuvant chemotherapy prior to surgery. Formalin-fixed paraffin-embedded (FFPE) tissue was used for RNA/DNA extraction and immunohistochemistry (IHC).

Histology slides of surgically resected specimens were reviewed, and cases of iCCA were classified into the smalland large-duct types according to previously described criteria and the WHO classification [1, 19]. Clinicopathological findings were obtained from electronically stored clinical records and histopathology reports. The findings of sequencing of KRAS and IDHI/2 and IHC for BAP1, p53 and SMAD4 in a previous study were used in the present study [1]. Mutations in KRAS (exons 2 and 3), IDHI (codon 132) and $I D H 2$ (codon 172) were analysed by Sanger sequencing using DNA extracted from FFPE tissue and following primers: forward 5'-AGGCCTGCTGAAAATGACTG-3' and reverse $5^{\prime}-$ GGTCCTGCACCAGTAATATGCA- 3 ' for exon 2 of KRAS; forward 5'-CCAGACTGTGTTTCTCCC TTCTC-3' and reverse 5'-AGAAAGCCCTCCCCAGTC CTCA-3' for exon 3 of $K R A S$; forward 5'-AAACAAATG TGGAAATCACC $-3^{\prime}$ and reverse 5'-TGCCAACATGAC TTACTTGA-3' for IDHI codon 132; forward 5'-AGA AGATGTGGAAAAGTCCC $-3^{\prime}$ and reverse 5'-CAGAGA CAAGAGGATGGCTAGG-3' for $I D H 2$ codon 172 . PostPCR-amplified products were separated by capillary electrophoresis on an ABI 3130xl Genetic Analyzer (Applied Biosystems, Foster City, CA, USA). Sequencing results were analysed using Sequencing Analysis 5.2 and SeqScape software (Applied Biosystems). IHC for BAP1, p53 and SMAD4 was conducted on one representative whole section in each case. Antibodies used were as follows: BAP1 (clone C-4; dilution 1:100, Santa Cruz Biotechnology), p53 (clone DO-7; dilution 1:300, Leica Microsystems, Wetzlar, Germany) and SMAD4 (clone B-8; dilution 1:100, Santa Cruz Biotechnology, Santa Cruz, CA). The completely negative 
nuclear staining of BAP1 was defined as a loss of expression, suggesting a BAP1 mutation. Diffuse nuclear staining of p53 was regarded as a positive result, indicating a p53 mutation. Cases with no detectable cytoplasmic or nuclear SMAD4 protein were scored as negative for SMAD4.

\section{IHC}

Tissue microarrays (TMAs) were constructed using 3 tissue cores ( $2 \mathrm{~mm}$ in diameter) obtained from one representative FFPE block of each case. Tissue cores were randomly obtained from tumour masses.

IHC for TET2 was performed using a Bond Max autostainer (Leica Microsystems) according to the manufacturer's protocol. Deparaffinised sections were subjected to a heat pretreatment in citrate buffer for $20 \mathrm{~min}$, followed by an incubation with a primary antibody against human TET2 (clone N2-2; dilution 1/100; GeneTex, Irvine, CA, USA). TET2 expression was observed in the cytoplasm and nuclei. Given that TET2 is a nuclear protein, only nuclear staining was assessed. Nuclear expression levels in TMA were semiquantitatively evaluated based on the percentage of positive cancer cells (score $0=0 \%$; score $1=1-33 \%$; score $2=34-66 \%$; score $3=67-100 \%)$ and the intensity of expression (score $0=$ negative; score $1=$ weak; score $2=$ moderate; score $3=$ strong). Weak intensity of the expression (score 1) was defined as faint staining requiring examination at a high-power magnification ( $\times 40$ objective lens), while strong intensity of the expression was defined as brisk staining with clear contrast to the background. Moderate intensity (score 2) was defined as staining between scores 1 and 3 . IHC scores in individual cases were assessed by multiplying percentage and intensity scores (range $0-9$ ). In cases, in which TET2 was negative in TMA, additional staining on whole sections was performed.

\section{Reverse-transcription quantitative PCR (RT-qPCR)}

Areas consisting predominantly of tumour cells were selected for RNA extraction under a microscope. The background liver parenchyma and large bile ducts (5 cases each) were used as a control group. Total RNA was extracted from FFPE sections using the AllPrep DNA/RNA FFPE Kit (Qiagen, Hilden, Germany). One microgram of RNA was treated with DNAse I Amplification Grade (AMPD1-1KT; Sigma-Aldrich, St. Louise, MO, USA) and then reverse transcribed using a High Capacity cDNA reverse transcription kit (4,368,814, Applied Biosystems) as per the manufacturer's protocol. Real-time PCR was conducted in triplicate using Luna ${ }^{\circledR}$ Universal qPCR Master Mix (New England BioLabs, Ipswich, MA, USA) as the SybrGreen Probe on an Ariamx Real-Time PCR System (Agilent, Santa Clara, CA, USA). Primer sequences for PCR were as follows: TET2 F
GCTTCCATTCTGGAGCTTTG, TET2 R GGACATGAT CCAGGAAGAGC. Large group-specific differences were observed in housekeeper genes therefore data presented as sample TET2 Ct from equivalent original input RNA (lower $\mathrm{Ct}$ indicates a higher expression level).

\section{Methylation analysis of the TET2 promoter}

Genomic DNA was extracted from areas in FFPE tissue sections that predominantly of tumour cells. DNA was extracted using the AllPrep DNA/RNA FFPE Kit (Qiagen). DNA content was assessed using the NanoDrop 2000c spectrophotometer (Thermo Fisher Scientific, Waltham, MA). Enzymatic conversion was performed on $1 \mu \mathrm{g}$ of DNA with the Enzymatic Conversion Module (New England Biolabs). Primer sequences for converted DNA were designed by Methprimer [12] and manufactured by Eurofins Genomics (Ebersberg, Germany). Semi-nested PCR was performed with the second primer (inner) containing 5'-prime octamer tags for the sequencing of barcodes. Primer sequences for amplification from enzymatically converted DNA were as follows: TET2 Outer F GGAAGTAAGATGGTTGTTTTT TAGG, TET2 Outer R AAACTTCCCTCTTCCCTCTTA ATATT, TET2 Inner F GGAAGTAAGATGGTTGTTTTT TAGG and TET2 Inner R ACACTACAAAATTTACTC CCCAATC. PCR was performed according to the Hot Start protocol for EpiMark Taq polymerase (New England Biolabs). The next-generation sequencing of PCR products was conducted by Amplicon-EZ (Genewiz, Leipzig, Germany), and the data obtained were initially analysed in the Unix shell to separate patients according to octamer barcodes and convert fastq files to fasta, followed by the BiQ Analyzer HT software [15], which revealed the methylation state of each individual $\mathrm{CpG}$ site.

\section{Statistical analysis}

Statistical analyses were performed using JMP statistical software (version 12; SAS Institute, Cary, NC, USA). Continuous variables not showing a bell-shaped distribution were assessed using the unpaired $t$ test or Mann-Whitney $U$ test, whereas categorical variables in each group were compared using the $X^{2}$ test or Fisher's exact test. Survival curves were constructed using the Kaplan-Meier method and compared between two groups by the Log-rank test. Univariate and multivariate analyses of multiple prognostic factors were performed on prognostic factors assessed by the Cox proportional hazards model. In RT-qPCR and DNA methylation analyses, values more or less than 2 standard deviations from the mean were considered to be outliers and, thus, were excluded. 


\section{Results}

\section{Clinicopathological features}

Among the 52 cases examined, 33 (63\%) were classified as the small-duct type and 19 (37\%) as the large-duct type. Eighteen patients (35\%) had a history of chronic liver disease and two (4\%) had features of established cirrhosis. Tumours were larger than $5 \mathrm{~cm}$ in 25 cases (48\%) and lymph node metastasis was confirmed in 14 cases (27\%). Intrahepatic metastasis including satellite nodules was observed in 16 cases $(31 \%)$. Molecular or IHC studies confirmed KRAS mutations in 9 cases (17\%), IDH1 mutations in $4(8 \%)$, the loss of BAP1 expression in 12 (13\%), the diffuse expression of p53 in 13 (25\%) and the loss of SMAD4 expression in 7 $(13 \%) . I D H 2$ was the wild type in all cases.

\section{TET2 mRNA expression and promoter methylation}

RT-qPCR revealed that the mRNA expression levels of TET2 were significantly higher in iCCA tissue than in background liver/bile duct tissue with a group average $\mathrm{Ct}$ difference of 1.5 PCR cycles, equivalent to a 2.8 -fold difference $(p=0.004$; Fig. 1A). However, no significant difference was observed in $\mathrm{CpG}$ methylation at $8 \mathrm{CpG}$ sites in the promoter of TET2 when all iCCA samples were compared to noncancer tissue (Fig. 1B)

\section{IHC for TET2}

Immunostaining for TET2 was conducted to examine the protein expression of TET 2 in 52 cases of iCCA relative to background liver/bile duct tissue. The non-neoplastic cholangiocytes of the small and large bile ducts did not show nuclear immunoreactivity for TET2. In contrast, 42 cases of iCCA (81\%) showed variable degrees of expression in TMA (Fig. 2). TET2 expression was located in the nuclei and cytoplasm, and the nuclear expression was slightly more pronounced than cytoplasmic staining in most cases. The remaining 10 cases of iCCA (19\%) were negative for TET2 in TMA. However, additional immunostaining on whole sections of those cases demonstrated focal TET2 expression. Based on IHC scores of TMA, cases were classified as TET2-high (IHC scores $4-9 ; n=25$ ) and TET2-low (IHC scores $0-3 ; n=27)$.

\section{Comparisons between TET2-high and -low cases}

Table 1 compares clinicopathological features between TET2-high and -low cases. No significant differences were observed in any of the parameters examined. No correlations were found between TET2 expression and histological subtypes. The frequencies of $K R A S$ or $I D H 1$ mutations and the loss of BAP1 or SMAD4 expression were also similar. $\mathrm{Ct}$ values in TET2 mRNA RT-qPCR on TET2-high cases were not significantly different from those for TET2-low cases (Table 1); however, both were significantly lower than those for non-cancer tissue (Fig. 3).

\section{TET2 promoter methylation analysis}

In order to examine the relationship between TET2 expression and TET2 promoter methylation, the methylation of $8 \mathrm{CpG}$ sites in the promoter region was quantitatively assessed. The mean value of methylation in the $8 \mathrm{CpG}$ sites did not significantly differ between TET2-high and -low cases $(2.31 \pm 0.15 \%$ vs. $2.62 \pm 0.21 \% ; p=0.238$; Table 1$)$. However, a comparison of individual $\mathrm{CpG}$ sites revealed that methylation levels at two CpG sites in TET2-high cases were significantly lower than those in TET2-low cases (Fig. 4).
Fig. 1 A RT-qPCR of TET2. $\mathrm{Ct}$ from an equivalent amount of input RNA. Lower Ct means higher expression. Data are the mean \pm SEM. $* p<0.05$. B Methylation levels at $8 \mathrm{CpG}$ sites in the promoter $\mathrm{CpG}$ island of TET2. Data are the mean \pm SEM. No significant differences at any $\mathrm{CpG}$ site

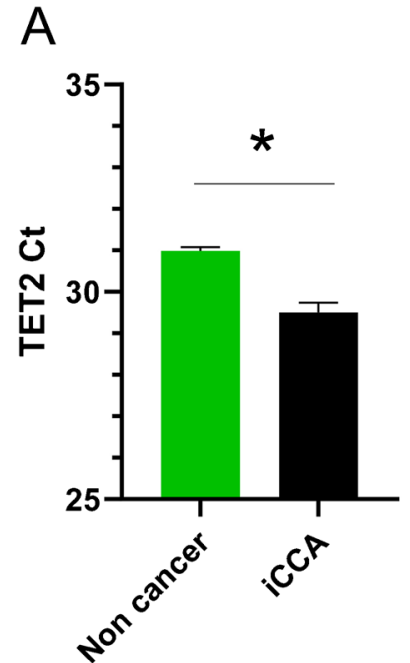


Fig. 2 Immunohistochemical expression of TET2 in iCCA. Representative examples of IHC intensity scores $0-3$ are shown. Variable degrees of nuclear TET2 expression are observed, and immunoreactivity is also present in the cytoplasm

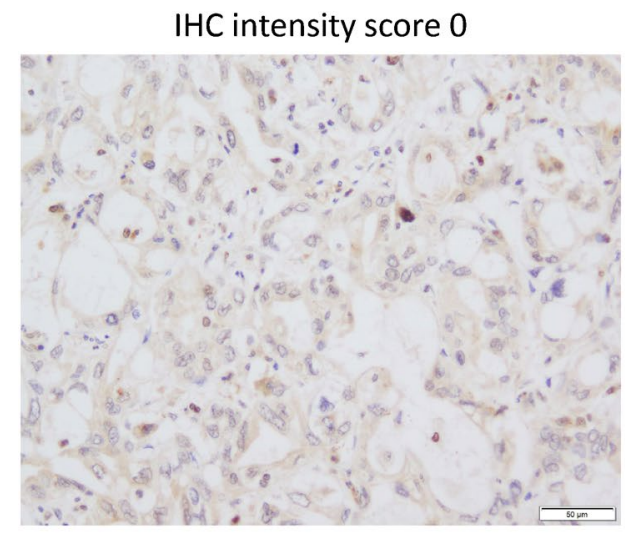

IHC intensity score 2

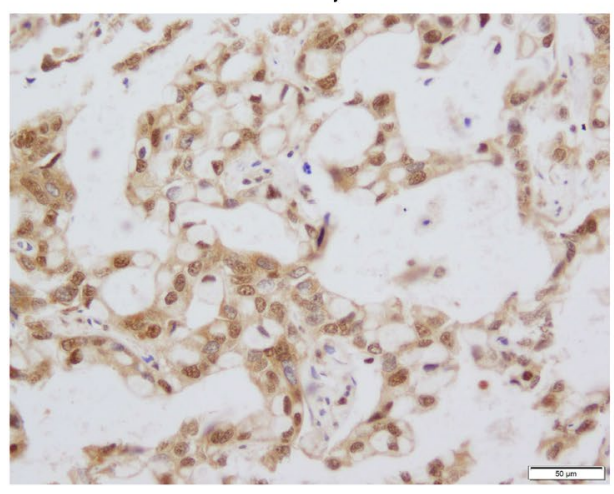

IHC intensity score 1

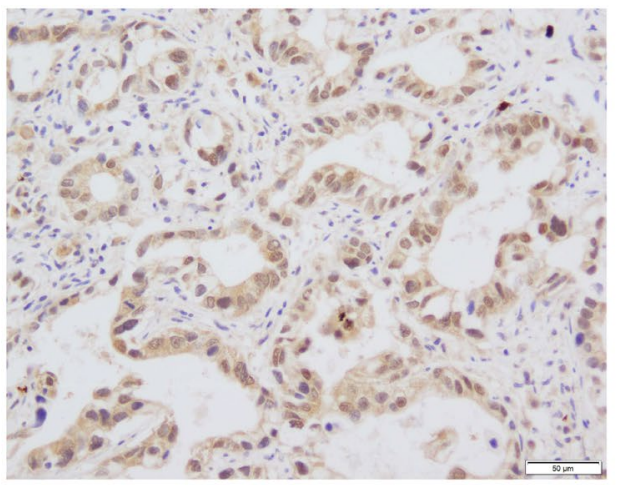

IHC intensity score 3

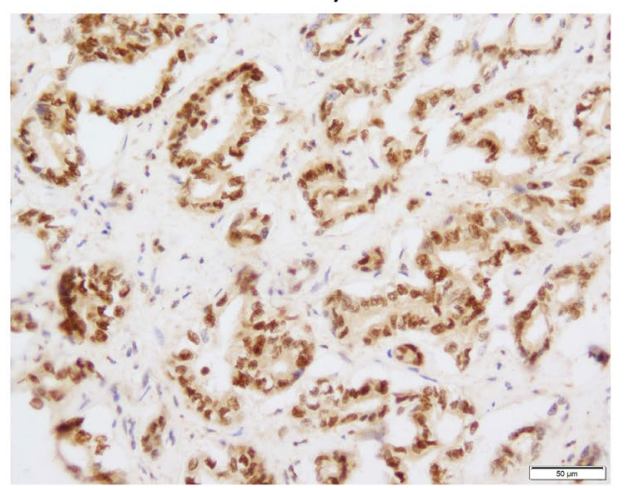

\section{Prognostic analysis}

As shown in Fig. 5, overall and recurrence-free survival were significantly worse in patients with TET2-high iCCA than in those with TET2-low iCCA ( $p=0.014$ or $p=0.044$, respectively). In a multivariate analysis, TET2 and other potential prognostic factors that showed a significant $(p<0.05)$ or slight difference $(p<0.20)$ in the univariate analysis were applied to the Cox proportional hazards model. TET2 overexpression, the large-duct histological type and intrahepatic metastasis were identified as independent poor prognostic factors in patients with iCCA (Table 2).

\section{Discussion}

The present study demonstrated that approximately $80 \%$ of iCCA cases expressed TET2. When these cases were classified into two groups based on IHC scores, the overexpression of TET2 did not correlate with histological types, a history of chronic liver disease, or lymph node or intrahepatic metastasis; however, it correlated with poor overall and recurrence-free survival. A multivariate analysis also identified TET2 overexpression as a prognostic factor independent of the histological type, tumour size, nodal involvement and intrahepatic metastasis. A quantitative methylation analysis of the promoter region suggested that the hypomethylation of two particular $\mathrm{CpG}$ sites contributed to the upregulation of TET2 expression in iCCA. The small difference in methylation values between the two groups is expected as the methylation change will only be occurring in the subpopulation of cells in the cancer tissue sample which express TET2. The tissues also contain non-TET2 expressing non-cancer cells (e.g., lymphocytes, stromal cells).

Distinct carcinogenetic processes between small- and large-duct iCCA have been highlighted by histology-molecular correlation studies $[1,8,13]$. Alterations in IDH1, IDH2 and $B A P 1$ are restricted to small-duct iCCA, while changes in KRAS, SMAD4, and MDM2 are more commonly observed in large-duct cancers [1, 9, 13]. However, molecular abnormalities that occur in either type have also been reported. The TP53 loss-of-function mutation is one of the most common molecular events potentially occurring in either subtype $[1,18]$. The epigenetic upregulation of TET2 is also suspected to contribute to the progression of both types of iCCA.

Multiple deep sequencing studies identified recurrent mutations in genes involved in chromatin remodelling (e.g., IDH1/2, ARIDIA, SMARCA and KDMA5A), highlighting a strong epigenetic component in iCCA carcinogenesis [7, 18]. A combined genetic and epigenetic analysis of iCCA revealed that cases with high mutation and hypermethylation levels had a worse prognosis than those with fewer genetic alterations and lower hypermethylation levels [7]. Epigenetic 
Table 1 Comparison of clinicopathological features between TET2high- and low cases

\begin{tabular}{|c|c|c|c|}
\hline & $\begin{array}{l}\text { TET2-high } \\
(n=25)\end{array}$ & $\begin{array}{l}\text { TET2-low } \\
(n=27)\end{array}$ & $p$ value \\
\hline Age (median, range) & $71(40-86)$ & $70(43-83)$ & 0.582 \\
\hline Gender $(\mathrm{M} / \mathrm{F})$ & $14 / 11$ & $15 / 12$ & 0.974 \\
\hline Chronic liver disease & $7(28 \%)$ & $11(41 \%)$ & 0.335 \\
\hline CA19-9 (median, range) & $157(1-43,400)$ & $107(1-829,298)$ & 0.614 \\
\hline CEA (median, range) & $3.1(0.3-27.6)$ & $4.0(1.0-405.6)$ & 0.384 \\
\hline Subtype & & & 0.282 \\
\hline Small duct & $14(56 \%)$ & $19(70 \%)$ & \\
\hline Large duct & $11(44 \%)$ & $8(30 \%)$ & \\
\hline Differentiation & & & 0.401 \\
\hline Well to moderate & $19(76 \%)$ & $23(85 \%)$ & \\
\hline Poor & $6(24 \%)$ & $4(15 \%)$ & \\
\hline Tumour size $(>2 \mathrm{~cm})$ & $23(92 \%)$ & $23(85 \%)$ & 0.442 \\
\hline Tumour size $(>5 \mathrm{~cm})$ & $11(44 \%)$ & $13(48 \%)$ & 0.764 \\
\hline Lymphatic invasion & $10(40 \%)$ & $12(44 \%)$ & 0.746 \\
\hline Venous invasion & $19(76 \%)$ & $18(67 \%)$ & 0.458 \\
\hline pT stage & & & 0.631 \\
\hline pT1-2 & $18(72 \%)$ & $21(78 \%)$ & \\
\hline pT3-4 & $7(28 \%)$ & $6(22 \%)$ & \\
\hline Lymph node metastasis & $8(32 \%)$ & $6(22 \%)$ & 0.427 \\
\hline Intrahepatic metastasis & $7(28 \%)$ & $9(33 \%)$ & 0.677 \\
\hline$K R A S$, mutation & $4(16 \%)$ & $5(19 \%)$ & 0.810 \\
\hline$I D H 1$, mutation & $2(8 \%)$ & $2(7 \%)$ & 0.936 \\
\hline $\begin{array}{l}\text { BAP1, loss of expres- } \\
\text { sion }\end{array}$ & $4(16 \%)$ & $8(30 \%)$ & 0.244 \\
\hline p53, strong expression & $8(32 \%)$ & $5(19 \%)$ & 0.262 \\
\hline $\begin{array}{l}\text { SMAD4, loss of expres- } \\
\text { sion }\end{array}$ & $4(16 \%)$ & $3(11 \%)$ & 0.606 \\
\hline $\begin{array}{l}\text { TET2, mRNA expres- } \\
\text { sion }(\mathrm{Ct})\end{array}$ & $29.2 \pm 0.38$ & $29.9 \pm 0.26$ & 0.127 \\
\hline $\begin{array}{l}T E T 2 \text {, promoter meth- } \\
\text { ylation }\end{array}$ & $2.31 \pm 0.15$ & $2.62 \pm 0.21$ & 0.238 \\
\hline
\end{tabular}

Fig. 3 RT-qPCR of TET2. Ct from an equivalent amount of input RNA. Lower Ct means higher expression. Data are the mean \pm SEM. ${ }^{*} p<0.05$ vs. the non-cancer group

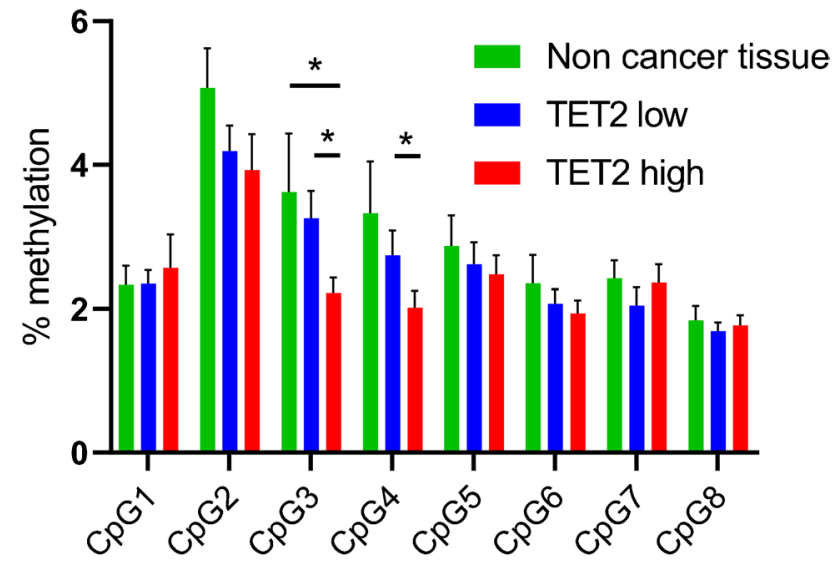

Fig. 4 Methylation levels at $8 \mathrm{CpG}$ sites in the promoter $\mathrm{CpG}$ island of TET2. Data are the mean \pm SEM. Separate $t$ tests were used to compare groups at each $\mathrm{CpG}$ site. ${ }^{*} p<0.05$

alterations in multiple genes, including $\mathrm{ROBO1}$, $\mathrm{ROBO} 2$, RPL22, TGFBR1 and TGFBR2, have been confirmed in iCCA; however, this is the first study to investigate epigenetic alterations in TET2 in iCCA [7].

Prior to the initiation of the present study, we hypothesised that TET2 may be down-regulated in iCCA, particularly small-duct type cases with wild-type $I D H 1$, similar to haematolymphoid malignancies and diffuse glioma [25]. The downregulation of TET2 may exert a similar epigenomic effect as the IDHI mutation, namely, an increase in DNA methylation levels. However, we observed the opposite effect; TET2 transcription levels in iCCA were higher than those in background liver/bile duct tissue. The protein expression levels of TET2 also did not correlate with histological types or $I D H 1$ mutations. These unexpected results may be attributed to the different roles of TET2 in haematopoietic cells and cholangiocytes. TET2 is highly expressed in non-neoplastic haematopoietic cells [11, 14]; therefore, TET2 silencing by promoter methylation disturbs the expression of various genes, ultimately leading to tumourigenesis. In contrast, TET2 expression is suppressed in non-neoplastic cholangiocytes, and, thus, the upregulation of TET 2 by promoter hypomethylation may contribute to the development or progression of iCCA.

Increases and decreases in DNA methylation $(5 \mathrm{mC})$ and 5-hmC at genes and intergenic regions have both been reported in cholangiocarcinoma [22]. The genome-wide level of $5 \mathrm{hmC}$ was previously reported to be decreased in iCCA (rather than increased, as was expected from the upregulated expression of TET2) [5]. However, it currently remains unclear whether these studies examined iCCA highly expressing TET2. The mechanisms by which the overexpression of TET2 influences tumour progression and patient survival may involve the altered regulation of a subset of downstream genes rather than an overall shift in the 
Overall survival

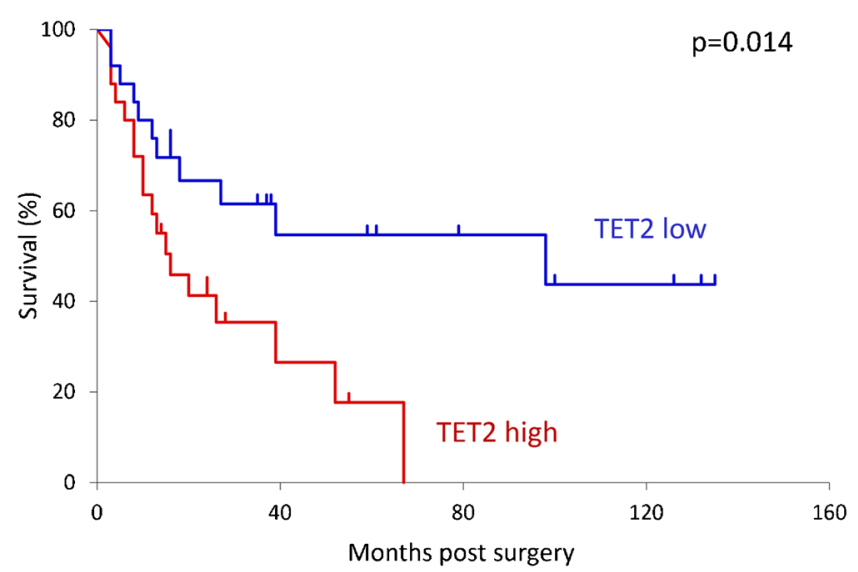

Recurrence-free survival

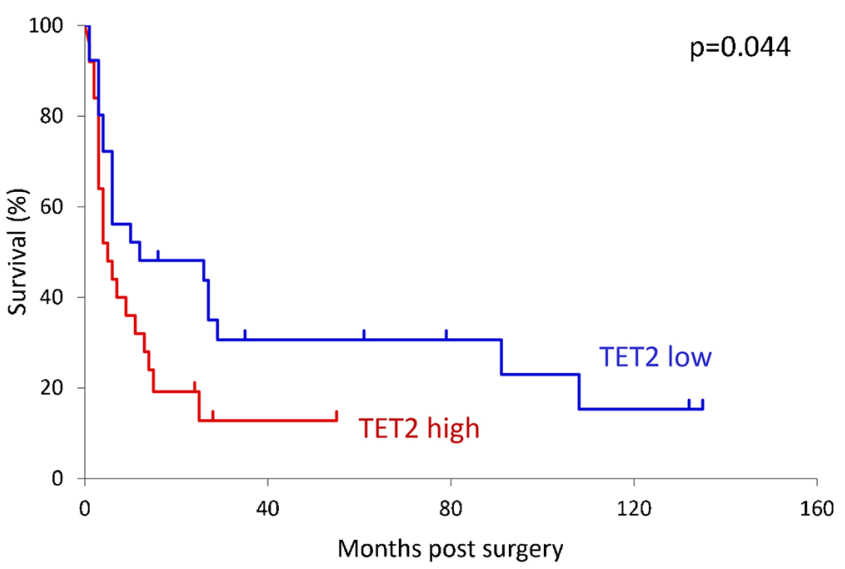

Fig. 5 Overall and recurrence-free survival curves of patients with iCCA. Overall and recurrence-free survival were significantly worse in patients with TET2-high iCCA

Table 2 Univariate and multivariate prognostic analysis

\begin{tabular}{|c|c|c|c|c|c|c|}
\hline & \multicolumn{3}{|c|}{ Univariate analysis } & \multicolumn{3}{|c|}{ Multivariate analysis } \\
\hline & HR & $95 \% \mathrm{CI}$ & $p$ value & HR & $95 \% \mathrm{CI}$ & $p$ value \\
\hline TET2-high expression & 2.58 & $1.19-5.89$ & 0.016 & 2.94 & $1.33-6.85$ & 0.007 \\
\hline Large-duct histological subtype & 1.91 & $0.90-4.06$ & 0.092 & 2.75 & $1.11-7.18$ & 0.028 \\
\hline Poor differentiated morphology & 1.65 & $0.60-3.90$ & 0.306 & & & \\
\hline Tumour size $>5 \mathrm{~cm}$ & 1.77 & $0.84-3.73$ & 0.129 & 1.46 & $0.63-3.46$ & 0.379 \\
\hline pT3 or pT4 & 1.12 & $0.44-2.53$ & 0.796 & & & \\
\hline Lymph node metastasis & 1.96 & $0.84-4.23$ & 0.115 & 2.20 & $0.86-5.31$ & 0.096 \\
\hline Intrahepatic metastasis & 1.77 & $0.80-3.71$ & 0.152 & 3.47 & $1.28-9.85$ & 0.015 \\
\hline
\end{tabular}

$H R$, hazard ratio; $C I$, confidence interval genome-wide epigenetic state. A focus for future research will be to identify which genes have altered $5 \mathrm{mC}$ and/or $5 \mathrm{hmC}$ in tumours overexpressing TET2.

A highly relevant study showed increases in the expression of TET 2 and $5 \mathrm{hmC}$ in a number of cancers that modulated the expression of $\mathrm{TNF}-\alpha$ signalling components and facilitated chemotherapy resistance in slow-cycling cancer cells by restraining proapoptotic signalling [24]. This effect of TET2 on a subpopulation of tumour cells with cancer initiation potential, which is not necessarily a factor influencing tumour size or stage, was consistent with our observations that the overexpression of TET 2 is a prognostic factor independent of these tumour parameters. Future studies that investigate the effectiveness of TET2 inhibitors, combined with chemotherapeutics against proliferative cancer cells, may be relevant for iCCA research.

Due the high level of IDHI mutations, which increase $5 \mathrm{mC}$, a number of studies have attempted to reduce methylation in cholangiocarcinoma using inhibitors in cell lines [3, $17,26]$. The present study raises a note of caution with this approach because it may activate TET2 by demethylating its promoter and, ultimately, decrease patient survival.

In conclusion, the present study demonstrated that the overexpression of TET2 is common in iCCA of both subtypes, and identified the high expression of TET2 as an independent poor prognostic factor. A quantitative methylation analysis suggested that hypomethylation in two particular CpG sites underlies the upregulation of TET2 in malignant cholangiocytes.

Acknowledgements We thank Dr Joana Viana for guidance in the bioinformatic methylation analysis.

Author contribution Concept and design (HY, NY, YZ); experiments and procedures (HY, AT, MA, TI, SC, TA, TF, NY, YZ); writing of article (HY, AT, NY, YZ); approval of the final version (HY, AT, MA, TI, SC, TA, TF, NY, YZ); supervision (NY, YZ).

Funding This study received financial support in Grant-in-Aid for Scientific Research from the Ministry of Education, Culture, Sports, Science and Technology in Japan (18H02630). This study was supported by core funding from the Foundation for Liver Research. 


\section{Declarations}

Conflict of interest The authors declare no competing interests.

Open Access This article is licensed under a Creative Commons Attribution 4.0 International License, which permits use, sharing, adaptation, distribution and reproduction in any medium or format, as long as you give appropriate credit to the original author(s) and the source, provide a link to the Creative Commons licence, and indicate if changes were made. The images or other third party material in this article are included in the article's Creative Commons licence, unless indicated otherwise in a credit line to the material. If material is not included in the article's Creative Commons licence and your intended use is not permitted by statutory regulation or exceeds the permitted use, you will need to obtain permission directly from the copyright holder. To view a copy of this licence, visit http://creativecommons.org/licenses/by/4.0/.

\section{References}

1. Akita M, Fujikura K, Ajiki T, Fukumoto T, Otani K, Azuma T, Itoh T, Ku Y, Zen Y (2017) Dichotomy in intrahepatic cholangiocarcinomas based on histologic similarities to hilar cholangiocarcinomas. Mod Pathol 30:986-997. https://doi.org/10.1038/modpa thol.2017.22

2. Akita M, Sofue K, Fujikura K, Otani K, Itoh T, Ajiki T, Fukumoto T, Zen Y (2019) Histological and molecular characterization of intrahepatic bile duct cancers suggests an expanded definition of perihilar cholangiocarcinoma. HPB (Oxford) 21:226-234. https:// doi.org/10.1016/j.hpb.2018.07.021

3. Andersen JB, Factor VM, Marquardt JU, Raggi C, Lee YH, Seo D, Conner EA, Thorgeirsson SS (2010) An integrated genomic and epigenomic approach predicts therapeutic response to zebularine in human liver cancer. Sci Transl Med 2:54ra77. https://doi.org/ 10.1126/scitranslmed.3001338

4. Bacher U, Haferlach C, Schnittger S, Kohlmann A, Kern W, Haferlach T (2010) Mutations of the TET2 and CBL genes: novel molecular markers in myeloid malignancies. Ann Hematol 89:643-652. https://doi.org/10.1007/s00277-010-0920-6

5. Dong ZR, Zhang C, Cai JB, Zhang PF, Shi GM, Gao DM, Sun HC, Qiu SJ, Zhou J, Ke AW, Fan J (2015) Role of 5-hydroxymethylcytosine level in diagnosis and prognosis prediction of intrahepatic cholangiocarcinoma. Tumour Biol 36:2763-2771. https:// doi.org/10.1007/s13277-014-2900-2

6. Figueroa ME, Abdel-Wahab O, Lu C, Ward PS, Patel J, Shih A, Li Y, Bhagwat N, Vasanthakumar A, Fernandez HF, Tallman MS, Sun Z, Wolniak K, Peeters JK, Liu W, Choe SE, Fantin VR, Paietta E, Löwenberg B, Licht JD, Godley LA, Delwel R, Valk PJ, Thompson CB, Levine RL, Melnick A (2010) Leukemic IDH1 and IDH2 mutations result in a hypermethylation phenotype, disrupt TET2 function, and impair hematopoietic differentiation. Cancer Cell 18:553-567. https://doi.org/10.1016/j.ccr.2010.11. 015

7. Goeppert B, Toth R, Singer S, Albrecht T, Lipka DB, Lutsik P, Brocks D, Baehr M, Muecke O, Assenov Y, Gu L, Endris V, Stenzinger A, Mehrabi A, Schirmacher P, Plass C, Weichenhan D, Roessler S (2019) Integrative analysis defines distinct prognostic subgroups of intrahepatic cholangiocarcinoma. Hepatology 69:2091-2106. https://doi.org/10.1002/hep.30493

8. Hayashi A, Misumi K, Shibahara J, Arita J, Sakamoto Y, Hasegawa K, Kokudo N, Fukayama M (2016) Distinct clinicopathologic and genetic features of 2 histologic subtypes of intrahepatic cholangiocarcinoma. Am J Surg Pathol 40:10211030. https://doi.org/10.1097/pas.0000000000000670

9. Kim SJ, Akita M, Sung YN, Fujikura K, Lee JH, Hwang S, Yu E, Otani K, Hong SM, Zen Y (2018) MDM2 amplification in intrahepatic cholangiocarcinomas: its relationship with large-duct type morphology and uncommon KRAS mutations. Am J Surg Pathol 42:512-521. https://doi.org/10.1097/pas.0000000000001006

10. Kim YH, Pierscianek D, Mittelbronn M, Vital A, Mariani L, Hasselblatt M, Ohgaki H (2011) TET2 promoter methylation in lowgrade diffuse gliomas lacking IDH1/2 mutations. J Clin Pathol 64:850-852. https://doi.org/10.1136/jclinpath-2011-200133

11. Langemeijer SM, Kuiper RP, Berends M, Knops R, Aslanyan MG, Massop M, Stevens-Linders E, van Hoogen P, van Kessel AG, Raymakers RA, Kamping EJ, Verhoef GE, Verburgh E, Hagemeijer A, Vandenberghe P, de Witte T, van der Reijden BA, Jansen JH (2009) Acquired mutations in TET2 are common in myelodysplastic syndromes. Nat Genet 41:838-842. https://doi.org/10. 1038/ng.391

12. Li LC, Dahiya R (2002) MethPrimer: designing primers for methylation PCRs. Bioinformatics 18:1427-1431. https://doi.org/10. 1093/bioinformatics/18.11.1427

13. Liau JY, Tsai JH, Yuan RH, Chang CN, Lee HJ, Jeng YM (2014) Morphological subclassification of intrahepatic cholangiocarcinoma: etiological, clinicopathological, and molecular features. Mod Pathol 27:1163-1173. https://doi.org/10.1038/modpathol. 2013.241

14. Lorsbach RB, Moore J, Mathew S, Raimondi SC, Mukatira ST, Downing JR (2003) TET1, a member of a novel protein family, is fused to MLL in acute myeloid leukemia containing the $\mathrm{t}(10 ; 11)$ (q22;q23). Leukemia 17:637-641. https://doi.org/10.1038/sj.leu. 2402834

15. Lutsik P, Feuerbach L, Arand J, Lengauer T, Walter J, Bock C (2011) BiQ Analyzer HT: locus-specific analysis of DNA methylation by high-throughput bisulfite sequencing. Nucleic Acids Res 39:W551-556. https://doi.org/10.1093/nar/gkr312

16. Ma B, Meng H, Tian Y, Wang Y, Song T, Zhang T, Wu Q, Cui Y, Li H, Zhang W, Li Q (2020) Distinct clinical and prognostic implication of IDH1/2 mutation and other most frequent mutations in large duct and small duct subtypes of intrahepatic cholangiocarcinoma. BMC Cancer 20:318. https://doi.org/10.1186/ s12885-020-06804-6

17. Moolmuang B, Singhirunnusorn P, Ruchirawat M (2016) Effects of 5-Aza-2'-deoxycytidine, bromodeoxyuridine, interferons and hydrogen peroxide on cellular senescence in cholangiocarcinoma cells. Asian Pac J Cancer Prev 17:957-963. https://doi.org/10. 7314/apjcp.2016.17.3.957

18. Nakamura H, Arai Y, Totoki Y, Shirota T, Elzawahry A, Kato M, Hama N, Hosoda F, Urushidate T, Ohashi S, Hiraoka N, Ojima H, Shimada K, Okusaka T, Kosuge T, Miyagawa S, Shibata T (2015) Genomic spectra of biliary tract cancer. Nat Genet 47:1003-1010. https://doi.org/10.1038/ng.3375

19. Nakanuma Y, Klimstra D, Komuta M, Zen Y (2019) Intrahepatic cholangiocarcinomaWorld Health Organization classification of digestive system tumours. Lyon, International Agency for Research on Cancer, pp 254-259

20. Nepal C, O'Rourke CJ, Oliveira D, Taranta A, Shema S, Gautam $\mathrm{P}$, Calderaro J, Barbour A, Raggi C, Wennerberg K, Wang XW, Lautem A, Roberts LR, Andersen JB (2018) Genomic perturbations reveal distinct regulatory networks in intrahepatic cholangiocarcinoma. Hepatology 68:949-963. https://doi.org/10.1002/ hep. 29764

21. O'Rourke CJ, Lafuente-Barquero J, Andersen JB (2019) Epigenome remodeling in cholangiocarcinoma trends. Cancer 5:335350. https://doi.org/10.1016/j.trecan.2019.05.002

22. O'Rourke CJ, Munoz-Garrido P, Aguayo EL, Andersen JB (2018) Epigenome dysregulation in cholangiocarcinoma. Biochim 
Biophys Acta Mol Basis Dis 1864:1423-1434. https://doi.org/ 10.1016/j.bbadis.2017.06.014

23. Patel JP, Gönen M, Figueroa ME, Fernandez H, Sun Z, Racevskis J, Van Vlierberghe P, Dolgalev I, Thomas S, Aminova O, Huberman K, Cheng J, Viale A, Socci ND, Heguy A, Cherry A, Vance G, Higgins RR, Ketterling RP, Gallagher RE, Litzow M, van den Brink MR, Lazarus HM, Rowe JM, Luger S, Ferrando A, Paietta E, Tallman MS, Melnick A, Abdel-Wahab O, Levine RL (2012) Prognostic relevance of integrated genetic profiling in acute myeloid leukemia. N Engl J Med 366:1079-1089. https:// doi.org/10.1056/NEJMoa1112304

24. Puig I, Tenbaum SP, Chicote I, Arqués O, Martínez-Quintanilla J, Cuesta-Borrás E, Ramírez L, Gonzalo P, Soto A, Aguilar S, Eguizabal C, Caratù G, Prat A, Argilés G, Landolfi S, Casanovas O, Serra V, Villanueva A, Arroyo AG, Terracciano L, Nuciforo P, Seoane J, Recio JA, Vivancos A, Dienstmann R, Tabernero J, Palmer HG (2018) TET2 controls chemoresistant slow-cycling cancer cell survival and tumor recurrence. J Clin Invest 128:38873905. https://doi.org/10.1172/jci96393

25. Rasmussen KD, Helin K (2016) Role of TET enzymes in DNA methylation, development, and cancer. Genes Dev 30:733-750. https://doi.org/10.1101/gad.276568.115
26. Shu Y, Wang B, Wang J, Wang JM, Zou SQ (2011) Identification of methylation profile of HOX genes in extrahepatic cholangiocarcinoma. World J Gastroenterol 17:3407-3419. https://doi.org/ 10.3748/wjg.v17.i29.3407

27. Turkalp Z, Karamchandani J, Das S (2014) IDH mutation in glioma: new insights and promises for the future. JAMA Neurol 71:1319-1325. https://doi.org/10.1001/jamaneurol.2014.1205

28. Yan H, Parsons DW, Jin G, McLendon R, Rasheed BA, Yuan W, Kos I, Batinic-Haberle I, Jones S, Riggins GJ, Friedman H, Friedman A, Reardon D, Herndon J, Kinzler KW, Velculescu VE, Vogelstein B, Bigner DD (2009) IDH1 and IDH2 mutations in gliomas. N Engl J Med 360:765-773. https://doi.org/10.1056/ NEJMoa0808710

Publisher's note Springer Nature remains neutral with regard to jurisdictional claims in published maps and institutional affiliations. 